\title{
MATERNAL AND PERINATAL COMPLICATIONS IN PRE-ECLAMPSIA
}

\author{
Sarita Acharya ${ }^{1}, \mathrm{MN} \mathrm{Pal}{ }^{2}$
}

\section{ABSTRACT}

INTRODUCTION: Hypertensive disorders of pregnancy is one of the major causes of maternal morbidity/mortalityleading to $10-15 \%$ of maternal deaths in low - and middle-income countries. Pre-eclampsia produces potentially lethal complications including abruptio placenta, disseminated intravascular coagulation, intracranial hemorrhage, hepatic failure, acute renal failure, and cardiovascular collapse. Intrauterine fetal growth restriction, intrauterine fetal demise and prematurity are the other related obstetric problems. The current study aimed to find the maternal and perinatal complications of pre- eclampsia in our context.

MATERIAL AND METHODS: A prospective study of 145 patients with the diagnosis of pre-eclampsia treated in a tertiary level teaching hospital between June 2011 to December 2013 was done. Hypertension in pregnancy, pre-eclampsia, severe pre-eclampsia and eclampsia were defined in the standard way. Maternal and perinatal complications were identified and analyzed.

RESULTS: Pre-eclampsia was detected in $6.02 \%$ of all deliveries. Maternal complications were abruptio placenta (11.03\%), eclampsia (8.27\%), HELLP syndrome (4.12\%), hypertensive encephalopathy ( $0.7 \%)$, acute renal failure $(0.7 \%)$ and maternal death $(0.7 \%)$. Fetal complications included preterm delivery $(17.93 \%)$, intra uterine growth restriction (10.34 $\%)$, intra uterine death $(8.30 \%)$ and neonatal death $(2.80 \%)$.

CONCLUSION: Pre-eclampsia is associated with increased maternal-perinatal complications. The adverse outcome can be minimized by more widespread use of prenatal care, education of primary medical care personnel, prompt diagnosis of high-risk patients and timely referral to tertiary medical centers.

KEYWORDS: Pre-eclampsia; Eclampsia; Complications

1 Lecturer, Department of Obstetrics and Gynecology, College of Medical Sciences, Bharatpur, Nepal

2 Professor, Department of Obstetrics and Gynecology, College of Medical Sciences, Bharatpur, Nepal

\author{
For Correspondence \\ Dr. Sarita Acharya \\ Lecturer, \\ Department of Obstetrics and Gynecology, \\ College of Medical Sciences, Bharatpur, Nepal \\ E-mail: saritaacharya142@yahoo.com
}




\section{INTRODUCTION}

Hypertensive disorder of pregnancy is one of the major causes of maternal morbidity and mortality. Overall, $10 \%-15 \%$ of direct maternal deaths are associated with pre-eclampsia and eclampsia in low- and middle-income countries. ${ }^{1,2}$ It occurs in $12-22 \%$ of pregnancies depending on the population and the definitions used. $^{3}$ Approximately $70 \%$ of hypertensive disorders of pregnancy are gestational hypertension/ preeclampsia and $30 \%$ is caused by chronic hypertension. ${ }^{4}$ Preeclampsia produces potentially lethal complications including abruptio placenta, eclampsia, disseminated intravascular coagulation, intracranial hemorrhage, HELLP syndrome, acute renal failure, and cardiovascular collapse. Most deaths in pre-eclampsia occur due to its complications and not due to hypertension per se. Intrauterine fetal growth restriction (IUGR), intrauterine fetal demise and prematurity are the most common fetal complications. All these clinical situations require prompt diagnosis and aggressive management in order to reverse adverse maternal-perinatal outcome. This study was carried out to find the extent of maternal and fetal complications of preeclampsia so that it will serve as a base line data for further studies on this subject matter.

\section{MATERIAL AND METHODS}

A prospective study of 145 patients with the diagnosis of preeclampsia treated between June 2011 to December 2013 in the department of obstetrics and gynecology of College of Medical Sciences Teaching Hospital was done. Patients were enrolled from both the antenatal clinics and antenatal ward. All the patients with pre-eclampsia who delivered in our centre were included. The patients with gestational hypertension and those with chronic hypertension or pre-eclampsia superimposed on chronic hypertension were excluded from the study. The diagnosis of pre-eclampsia and eclampsia was based on the criteria defined by national high blood pressure education programme working group on high blood pressure in pregnancy. ${ }^{5}$ Severe pre-eclampsia was diagnosed with one or more of the following criteria: blood pressure $\geq 160 / 110$, proteinuria of at least $5 \mathrm{~g} / 24 \mathrm{~h}$, oliguria $(<600 \mathrm{ml} / 24 \mathrm{~h}$ or $<30$ $50 \mathrm{ml} / \mathrm{h}$ ), intrauterine fetal growth restriction, oligohydramnios (amniotic fluid index $<50 \mathrm{~mm}$ ), symptoms suggesting end organ failure such as headache, visual disturbances, epigastric pain, medical complications involving pulmonary edema, cerebral edema, acute renal insufficiency, HELLP syndrome (hemolysis, elevated liver enzymes, low platelet count). Blood pressure was controlled with alphaMethyldopa or Nifedipine or both. Nifedipine was administered orally to control high blood pressure values $\geq 160 / 110 \mathrm{mmHg}$. Magnesium Sulphate was used for the control of seizure in eclampsia or for prevention of seizure in severe pre-eclampsia. The Pritchard regimen was followed (4 $\mathrm{g}$ intravenous along with $10 \mathrm{mg}$ i.m loading dose followed by $5 \mathrm{mg}$ intramuscular every 4 hourly until $24 \mathrm{~h}$ after delivery). Dexamethasone, four doses of $6 \mathrm{mg}$, was administered intramuscularly in $48 \mathrm{hrs}$ to accelerate the fetal lung maturity in cases with gestational age of $28-34$ weeks. Prostaglandin analogue or oxytocin infusion was preferred to induce or augment labour respectively according to Bishop Score in cases which were decided to be delivered.

Statistical analysis was done by using Statistical Package for the Social Sciences Software (SPSS) Programme for windows $^{\circledR}$ version 18 . Statistical significance was accepted at the 5 percent level $(P$ value $<0.05)$. Chi- square test was used wherever applicable.

\section{RESULTS}

In this study out of 2305 deliveries conducted between June 2011 to December 2013,145 (6.02\%) patients were found to be complicated with pre-eclampsia. The mean age of the patient was 24.42years. (Table 1)

Table 1: Demographic and clinical parameters

\begin{tabular}{|l|l|}
\hline Variable(s) & Values( percentage) \\
\hline Total number of patients & 145 \\
\hline Age in years* & $24.42 \pm 4.56(16-37)$ \\
\hline Gravida & \\
\hline Primigravida & $88(60.7)$ \\
\hline \multicolumn{1}{|c|}{ Multigravida } & $57(39.3)$ \\
\hline Parity & \\
\hline Nullipara & $95(65.5)$ \\
\hline Multipara & $50(34.5)$ \\
\hline Period of gestation ( weeks)* & $37.47 \pm 3.0(22.6-42.4)$ \\
\hline Presenting symptoms and signs & \\
\hline Ankle edema & $82(56.6)$ \\
\hline Headache & $55(37.9)$ \\
\hline Blurring of vision & $22(15.2)$ \\
\hline Epigastric pain & $14(9.7)$ \\
\hline Vaginal bleeding & $9(6.2)$ \\
\hline Convulsion & $5(3.4)$ \\
\hline Preeclampsia severity & \\
\hline Mild & $63(43.4)$ \\
\hline Severe & $82(56.6)$ \\
\hline & Mean \pm SD(range) \\
&
\end{tabular}

Eighty-three percentages of the patients were in the age range 
of 20- 34 years. There was similarity between patients of mild and severe pre-eclampsia in terms of age, gravida and parity. Majority of the mothers $(70 \%)$ who were affected by preeclampsia were from rural area. Fifty eight percent of the patient were with term pregnancy, $38.6 \%$ were preterm and $2.6 \%$ were postterm at the time of presentation.

Twenty nine of the patients with severe pre-eclampsia received Inj. MgSO4, while 12 of them had seizure (with proteinuria) and none of the patients in severe pre-eclamptic group who received Inj.MgSO4 prophylactically developed seizure. Cesarean section was the mode of delivery in 50.3\% of the patients, while $45.5 \%$ of them had normal vaginal delivery and $4.1 \%$ had undergone instrumental delivery. Among 145 patients with pre-eclampsia, 119 (82\%) of the patients required anti-hypertensive medicines either during antepartum, intrapartum or postpartum period. Among them, 76 were in severe pre-eclampsia and 43 in mild pre-eclampsia group.

The most frequently encountered maternal complications were abruptio placenta, eclampsia and HELLP syndrome. (Table 2)

Table 2: Maternal complications of pre-eclampsia

\begin{tabular}{|c|c|c|c|}
\hline Maternal complications & $\begin{array}{l}\text { Mild pre- } \\
\text { eclampsia }\end{array}$ & $\begin{array}{l}\text { Severe pre- } \\
\text { eclampsia }\end{array}$ & Total \\
\hline Abrutio placenta & 2 & 14 & 16 \\
\hline Eclampsia & 3 & 9 & 12 \\
\hline Oligohydramnios & 1 & 6 & 7 \\
\hline HELLP syndrome & 0 & 6 & 6 \\
\hline PPH & 1 & 0 & 1 \\
\hline Acute renal failure & 0 & 1 & 1 \\
\hline Hypertensive encephalopathy & 0 & 1 & 1 \\
\hline Hypertensive retinopathy & 0 & 1 & 1 \\
\hline Maternal mortality & 0 & 1 & 1 \\
\hline Total & 7 & 39 & 46 \\
\hline
\end{tabular}

liver enzymes, low platelet count

Other complications were oligohydramnios, acute renal failure, hypertensive encephalopathy, hypertensive retinopathy. Abruptio placenta was diagnosed in severely preeclamptic and mildly preeclamptic groups with incidence of $17.07 \%$ and $3.17 \%$ cases respectively, with a statistically significant difference $(\mathrm{P}=0.002)$. Maternal mortality occurred in $1(0.7 \%)$ case due to pulmonary edema.

Among the fetal complications prematurity was the most common $((17.93 \%)$ followed by intra uterine growth restriction $(10.34 \%)$, intra uterine death $(8.30 \%)$ and neonatal death $(2.80 \%)$. (Table3)

Table 3: Fetal complications of pre-eclampsia

\begin{tabular}{|l|l|l|l|}
\hline Fetal outcome & $\begin{array}{l}\text { Mild pre- } \\
\text { eclampsia }\end{array}$ & $\begin{array}{l}\text { Severe pre- } \\
\text { eclampsia }\end{array}$ & Total \\
\hline Normal & 49 & 39 & 88 \\
\hline Preterm & 8 & 18 & 26 \\
\hline IUGR & 2 & 13 & 15 \\
\hline IUD & 2 & 10 & 12 \\
\hline NND & 2 & 2 & 4 \\
\hline Total & 63 & 82 & 145 \\
EUR: intra uterine growth restriction, HO: intra uterine
\end{tabular}

death, NND: neonatal death

Adverse fetal outcome and complications were significantly associated with the severity of pre-eclampsia $(\mathrm{p}=0.03)$.

\section{DISCUSSION}

Pre-eclampsia is best described as a pregnancy-specific syndrome that can affect virtually every organ system. The exact incidence of pre-eclampsia is unknown but it has been reported to be approximately 5-8\%. ${ }^{6}$ It was identified in $6.02 \%$ of the total deliveries in our study. The mean age of the patients was 24.42 years, $60.7 \%$ were primigravida and $69.7 \%$ of the patients were unbooked. Singhal et al. reported that mean age of the patients was 24.04 years and 73\% were primigravida, $82 \%$ of the patients were unbooked. ${ }^{7}$ Headache, blurring of vision and epigastric pain were the antecedent symptoms in $37.5 \%, 15.2 \%$ and $9.2 \%$ of the patients, respectively. Singhal et al. reported headache in $44 \%$, epigastric pain in $20 \%$ and blurring of vision in $8 \%$.

Among 145 patients of pre-eclampsia, 56.6\% had severe preeclampsia which was similar to the result of Yucesoy et al. (54.11\%); however, there was differences in the incidence of mild pre-eclampsia ( $43.4 \%$ vs. $34.50 \%){ }^{8}$

Cesarean section was the mode of delivery in $50.3 \%$ of the 
patients while $45.5 \%$ had normal vaginal delivery and $4.1 \%$ had undergone instrumental delivery. In the study done by Vidhyadhar et al. rate of caesarean delivery, vaginal delivery and instrumental delivery were $35 \%, 59 \%$ and $6 \%$ respectively. ${ }^{9}$ Vaginal delivery is recommended for the severe preeclamptic women in the absence of obstetric indication for caesarean section. Elective abdominal delivery may be preferred in cases before 32 weeks with IUGR and oligohydramnios. ${ }^{10}$ Among 145 patients with hypertensive disorder of pregnancy, $119(82 \%)$ of the patients required antihypertensive medicines either during antepartum, intrapartum or postpartum period. Among them, 76 were in severe preeclampsia and 43 in mild pre-eclampsia group.

Overall maternal complications occurred in $31.7 \%$ which comprised of abruptio placenta (11\%), eclampsia (8.3\%), oligohydramnios $(4.8 \%)$, HELLP syndrome (4.1\%) acute renal failure $(0.7 \%)$, post-partum hemorrhage $(0.7 \%)$, hypertensive encephalopathy $(0.7 \%)$ and hypertensive retinopathy $(0.7 \%)$. The incidence of abruptio placenta in severely preeclamptic and mildly preeclamptic group was $17.07 \%$ and $3.17 \%$ respectively, the difference was statistically significant $(\mathrm{P}=0.002)$. Our findings were similar to that reported by Vidhyadhar et al. in which the incidence of abruptioplancenta in severe and mild preeclampsia were $19.04 \%$ and $5.12 \%$ respectively. ${ }^{9}$ Contrary to these only $7.7 \%$ of the severely pre-eclamptic patients had abruptio placenta. ${ }^{11}$

In our study $8.3 \%$ of the pre-eclampsia was complicated by eclampsia which is less as compared to that reported by Vidhyadhar et al. (19\% eclampsia). ${ }^{9}$ The incidence of eclampsia in severe pre-eclamptic patients was higher $(11 \%$ vs. $6.3 \%)$ compared to that of Nankali et al. ${ }^{11}$ Oligohydramnios was present in $21.68 \%$ of the pre eclampsia." This is incontrast to our result of $4.8 \%$ of oligohydramnios. None of the patients with mild preeclampsia had HELLP syndrome, while $7.3 \%$ in the severe pre-eclampsia group developed the syndrome. There is wide variations $(0.3-11 \%)$ in the incidence of this syndrome in the literature. ${ }^{8,11}$ The incidence of PPH $(2 \%)$ and renal failure (2\%) were higher than our study.

Maternal mortality occurred in 1 case $(0.7 \%)$ and she was diagnosed as pulmonary edema. She was an unbooked patient who had few antenatal visits at health post and was referred for high blood pressure with dyspnea. Maternal mortality was nil in Tuffnell et al. ${ }^{12}$ series, while Singhal et al. ${ }^{7}$ reported $8 \%$ maternal mortality associated with pre-eclampsia. Most of the deaths $(89.5 \%)$ were in unbooked women and the most common causes of death were acute renal failure, cardiopulmonary failure, disseminated intravascular coagulopathy and cerebrovascular accident. ${ }^{13}$

Perinatal complications occurred in $39.3 \%$ of the preeclampsia patients. Prematurity was the most common complication seen in $17.93 \%$ of the deliveries. It was found in $11.1 \%$ of mild preeclampsia and $21.9 \%$ in severe preeclampsia, which was statistically significant $(\mathrm{p}=0.03)$. The rate of prematurity in mild preeclampsia and severe preeclampsia were $17.99 \%$ and $47.62 \%$ respectively. ${ }^{9}$ Singhal et al. reported prematurity in $67.33 \%$ of preeclampsia patients. ' IUGR was the next common complication seen in $10.34 \%$ of pre eclampsia. In contrary to our findings Singhal et al. reported the incidence of IUGR to be $23.47 \%$ in preeclampsia. ${ }^{7}$ In mild pre-eclampsia the IUGR was $10.3 \%$ and in severe pre- eclampsia it was $15.8 \%$. The rate of IUGR in mild and severe pre-eclampsia were $7.69 \%$ and $26.19 \%$ respectively. ${ }^{9}$ One of the fetal complications was IUD which occurred in $8.3 \%$ of the pre-eclampsia cases. This figure is markedly low ( $8.3 \%$ vs. $28.57 \%)$ as reported by Singhal et al. ${ }^{7}$ Perinatal mortality was $11 \%$ in our study. Perinatal mortality in literature ranged between $4.7 \%$ to $41.6 \% .^{7,9,12,14}$ This study has some limitations. First, it is a single centre based study so the results may not be applicable to other populations. Second, the sample size is relatively small. So we recommend for further multicenter study with larger sample size in order to know the extent of the problems of pre-eclampsia and measures to tackle them in our context.

\section{CONCLUSION}

Pre-eclampsia is associated with increased risk of adverse maternal and perinatal outcome. The complications of severe pre-eclampsia and eclampsia could be prevented by more widespread use of prenatal care, education of primary medical care personnel, prompt diagnosis of high-risk patients and timely referral to tertiary medical centers.

\section{ACKNOWLEDGEMENT}

We acknowledge the contributions and hard work of our resident Dr. Arun Kumar Gurung in this study.

\section{REFERENCES}

1. Duley L. Maternal mortality associated with hypertensive disorders of pregnancy in Africa, Asia, Latin America and the Caribbean. BrJObstetGynaecol 1992; 99:547-53. http://dx.doi.org/10.1111/j.1471-0528.1992.tb13818.x PMid:1525093

2. Khan KS, Wojdyla D, Say L, et al. WHO analysis of causes of 
maternal death: a systematic review. Lancet 2006; 367:106674. http://dx.doi.org/10.1016/S0140-6736(06)68397-9

3. Walker JJ. Preeclampsia. Lancet 2000; 356:1260-5. http://dx.doi.org/10.1016/S0140-6736(00)02800-2

4. Matthys LA, Coppage KH, Lambers DS, Barton JR, Sibai BM. Delayed postpartum preeclampsia: an experience of 151 cases. Am JObstetGynecol 2004; 90(5): 1464-6. http://dx.doi.org/10.1016/j.ajog.2004.02.037PMid:15167870

5. National high blood pressure education program working group report of the national high blood pressure education program working group on high blood pressure in pregnancy. Am J Obstet Gynecol 2000;183: S1S22. http://dx.doi.org/10.1067/mob.2000.107928

6. Diagnosis and management of preeclampsia and eclampsia. American college of obstetrics and gynecology (ACOG) practice bulletin. ObstetGynecal 2002; 99: 159-67. http://dx.doi.org/10.1016/S0029-7844(01)01747-1

7. Singhal SR, Deepika, Anshu, Nanda S. Maternal and perinatan outcome in severe preeclampsia and eclampsia.Journal of South Asian Federation of Obstetrics and Gynaecology (JSAFOG) 2009;1(3): 25-8.

8. Yucesoy G, Ozkan S, Bodur H, Tan T, Caliskan E, Vural B, Corakci A. Maternal and perinatal outcome in pregnancies complicated with hypertensive disorder of pregnancy: a seven year experience of a tertiary care center. Arch Gynecol Obstet. 2005;273:439.

http://dx.doi.org/10.1007/s00404-005-0741-3PMid:15834580

9. Vidhyadhar BB, Purushottam AG, Aditi SM. Maternal and foetal outcome in pregnancy induced hypertension: a study from rural tertiary care teaching hospital in India. International Journal of Biomedical Research 2011; 12:595 $\square 99$.
10. Jose Villar, Guillermo Carroli et al. Preeclampsia, gestational hypertension and intrauterine growth restriction, related or independent conditions? Am. J. Obstet Gynecol 2006; 94: 921

31.http://dx.doi.org/10.1016/j.ajog.2005.10.813 PMid:16580277

11. A. Nankali, Sh. Malek-khosravi, M. Zangeneh, M. Rezaei, Z. Hemati, M. Kohzadi. Maternal Complications Associated with Severe Preeclampsia. J ObstetGynaecol India. 2013 ; 63(2): 112115.

http://dx.doi.org/10.1007/s13224-012-0283-OPMid:24431616 PMCid:PMC3664684

12. Tuffnell DJ, Jankowicz D, Lindow SW, Lyons G, Mason GC, Russell IF, et al. Outcome of severe preeclampsia/ eclampsia. Yorkshire 1999/2003.Br. JObstet Gynecol. 2005; 112 :875-80 http://dx.doi.org/10.1111/j.1471-0528.2005.00565.x PMid:15957986

13. Igberase $G O$, Ebeigbe PN. Eclampsia:ten-years of experience in a rural tertiary hospital in the Niger delta. Nigeria. JObstet Gynaecol. 2006; 26(5): 414-7.

http://dx.doi.org/10.1080/01443610600720113

PMid:16846866

14. Al Inizi ST, Sharara H, Ahmed B. Eclampsia in Quatar: maternal and fetal outcomes, possible preventive measures. Mid East $J$ Emerg Med 2005; 5: 1-6. 